\title{
HUBUNGAN TINGKAT KEBISINGAN DENGAN STRESS KERJA PADA PEKERJA PABRIK BATU ALAMDI DESA KEPUH KABUPATEN CIREBON
}

\author{
Fajr Lintang Pinilih ${ }^{1}$, Yani Kamasturyani ${ }^{2}$, Akhmad Fauzi ${ }^{3}$ \\ ${ }^{1}$ Program Studi Kesehatan Masyarakat, STIKes Mahardika Cirebon, Jl. Terusan SekarKemuning \\ No.199 Evakuasi Kota Cirebon \\ ${ }^{2}$ Lembaga Penelitian dan Pengabdian Masyarakat, Jl. Terusan SekarKemuning No.199 Evakuasi \\ Kota Cirebon \\ ${ }^{3}$ Lembaga Penelitian dan Pengabdian Masyarakat, Jl. Terusan SekarKemuning No.199 Evakuasi \\ Kota Cirebon
}

\begin{tabular}{l}
\hline ARTICLE INFORMATION \\
\hline Received: July, 15, 2021 \\
Revised: July, 23, 2021 \\
Available online: September, 20, 2021 \\
KEYWORDS \\
Noise Level, Work Stress, Natural Stone \\
Factory, Environmental Health \\
CORRESPONDENCE
\end{tabular}

Fajr Lintang Pinilih,

STIKes Mahardika, Indonesia

E-mail: fajrlintangp98@gmil.com

\begin{abstract}
A B S T R A C T
Industrial Work Environment Health is an effort to prevent disease or health problems from risk factors in the industrial work environment consisting of physical, chemical, biological, ergonomic, and sanitary hazard factors to realize a healthy industrial work environment quality. The purpose of this study was to determine the relationship between noise level and work stress on natural stone factory workers in Kepuh Village, Cirebon Regency. This research method is quantitative using an observational analytical research design with a cross-sectional approach. The sampling technique used is total sampling. The sample used is all natural stone factory workers in the village of Kepuh, Cirebon district as many as 59 people. The instrument used in this research is to use a measuring instrument, namely Sound Level Meter and a questionnaire with the checklist method. The results showedthat most of the production area of the noisy factory was $(79.7 \%)$ the two variables were interrelated with the proven $p$ value $=0.000$. The conclusion of the study shows that there isa significant relationship between Noise Level and Work Stress on Natural Stone Factory Workers in Kepuh Village, Cirebon Regency.
\end{abstract}

\section{A $\mathbf{B}$ S $\mathbf{T} \mathbf{R}$ A $\mathbf{K}$}

Kesehatan Lingkungan Kerja Industri adalah upaya pencegahan penyakit atau gangguan kesehatan dari faktor risiko lingkungan kerja industri yang terdiri dari faktorbahaya fisik, kimia, biologi, ergonomi, dan sanitasi untuk mewujudkan kualitas lingkungan kerja industri yang sehat. Tujuan dari penelitian ini untuk mengetahui Hubungan Tingkat Kebisingan Dengan Stress Kerja Pada Pekerja Pabrik Batu Alam Di Desa Kepuh Kabupaten Cirebon. Metode penelitian ini adalah kuantitatif menggunakan desain penelitian analitik observasional dengan pendekatan cross-sectional. Teknik sampling yang digunakan adalah total sampling. Sampel yag digunakan adalah seluruh pekerja pabrik batu alam di desa kepuh kabupaten Cirebon sebanyak 59 orang. Instrumen yang digunakan dalam penelitian ini adalah dengan menggunakan alat ukur yaitu Sound Level Meter dan kuesioner dengan metodecheklist. Hasil penelitian menunjukkan bahwa sebagaian besar area produksi pabrik bising sebesar $(79,7 \%)$ kedua variabel saling berhubungan dengan dibuktikan nilai $p$ value $=0,000$. Kesimpulan penelitian menunjukkan terdapat hubungan yang signifikan antara Hubungan Tingkat Kebisingan Dengan Stress Kerja Pada Pekerja Pabrik Batu Alam Di Desa Kepuh Kabupaten Cirebon. 


\section{PENDAHULUAN}

Menurut International LabourOrganization (ILO) kesehatan dan keselamatan kerja atau Ocupational Safety and Health adalah meningkatan dan memelihara derajat tertinggi semua pekerjabaik secara fisik, mental, dan kesejahteraan sosial di semua jenis pekerjaan, mencegah terjadinya gangguan kesehatan yang diakibatkan oleh pekerjaan, melindungi pekerja pada setiap pekerjaan dari risiko yang timbuk dari faktor faktor yang dapat mengganggu kesehatan, menempatkan dan memelihara pekerja di lingkungan kerja yang sesuai dengan kondisi fisologis dan psikologis pekerja dan untuk menciptakan kesesuaianantara pekerjaan dengan pekerja dan untuk menciptakan kesesuaian antara pekerjaan dengan pekerja dan setiap orang dengan tugasnya (International LabourOrganization, 2013).

Kesehatan Lingkungan Kerja Industri adalah upaya pencegahan penyakitatau gangguan kesehatan dari faktor risiko lingkungan kerja industri yang terdiri dari faktor bahaya fisik, kimia, biologi, ergonomi, dan sanitasi untuk mewujudkan kualitas lingkungan kerja industri yang sehat. Dalam kesehatan lingkungan kerja, memiliki nilai atau pedoman yang harusdipenuhi dan dilaksanakan di tempat kerja yaitu Nilai Ambang Batas atau NAB. NAB atau Nilai Ambang Batas adalah intensitas pajanan ratarata bahaya fisik atau kimia yang bisa diterima oleh seluruh pekerja tanpa mengakibatkan gangguan kesehatan atau penyakit dalam pekerjaan dalam sehari pada waktu yang tidak melebihi 8 jam perhari atau 40 jam perminggu. (PERMENKES No. 70 Tahun 2016).

Riset Kesehatan Dasar (Riskesdas) tahun 2018 menunjukan bahwa prevalensi penduduk Indonesia pada pendduduk umur $\geq 15$ tahun yang mengalami gangguan mental emosional atau stress mengalami peningkatan adalah sebesar 19,8\% (Riskesdas, 2018).

Stress merupakan keadaan tegang secara biopsikososial karena banyak tugas-tugas perkembangan yang dihadapi orang sehari-hari, baik dalam kelompok sebaya, keluarga, sekolah, maupun pekerjaan. Reaksi emosional yang dihasilkan dari situasi stress meliputi kecemasan,kemarahan dan agresi, serta apati dan depresi. Di dalam lingkungan kerja, terdapat stress kerja yaitu ketegangan yangsering dialami oleh karyawan yang dapat mengganggu situasi kerja serta konsentrasi dalam menyelesaikan tugas (Rustiana \& Cahyati, 2012).

Stres kerja juga terjadi di Indonesia. Beberapa studi terakhir menyimpulkan bahwa setiap tahunnya kasus stres diIndonesia meningkat dengan cepat dan berpotensi menimbulkan dampak sosial, emosional, psikologis dan berbagai masalah yang berhubungan dengan kesehatan. Berdasarkan penelitian yangdilakukan Regus pada tahun 2012 yang diperoleh dari CFO Innovation Asia Staff (2016) menyatakan bahwa Indonesia mengalami tingkat stres kerja dengan angka 73\%. Peningkatan terjadi sebesar $9 \%$ dari tahun sebelumnya yang berada di tingkat $64 \%$. Tingginya persentase stress kerja di Indonesia, sering dipengaruhi oleh faktor di dalam negeri dan faktor individu dan pekerjaan.

Intensitas kebisingan sering dapat menyebabkan penurunan performasi kerja,sebagai salah satu penyebab stress dan gangguan kesehatanlainnya. Stress yang disebabkan karena pemaparan kebisingan dapat menyebabkan terjadinya kelelahan dini, kegelisahan dan depresi. Stress karena kebisingan juga menyebabkan cepat marah, sakit kepala dan gangguan tidur (Budiyanto \& Pratiwi, 2010).

Berdasarkan hasil studi pendahuluan pada Pabrik Batu Alam di Desa Kepuh ditemukan bahwa beberapa pekerja yang mengalami penurunan konsentrasi dalambekerja di area yang bising, seperti otottegang yang mengakibatkan sakit kepala atau pusing dan mengalami gangguantidur. Berdasarkan uraian di atas peneliti ingin meneliti Hubungan Tingkat Kebisingan Dengan Stress 
Kerja Pada ParaPekerja Pabrik Batu Alam Di Desa Kepuh Kabupaten Cirebon.

\section{METODE}

Jenis atau rancangan penelitian ini adalah kuantitatif menggunakan desain penelitian analitik observasional dengan pendekatan cross-sectional yaitu penelitian untuk mencari hubungan antar variabel. Pendekatan cross secsional ialah suatu penelitian untuk mempelajari dinamikakolerasi antara faktor-faktor risiko dengan efek, dengan cara pendekatan, observasi atau pengumpulan data sekaligus pada suatu saat (point time approach) yang artinya tiap subjek penelitian hanya diobservasi sekali saja dan pengukuran dilakukan terhadap status karakter atau variabel subjek pada saat pemeriksaan (Notoatmodjo, 2018). Penelitian ini mendeskripsikan apakah ada hubungantingkat kebisingan dengan stress kerjapada pekerja pabrik batu alam.

Variabel independen sering disebut sebagai variabel bebas. Variabel bebas merupakan variabel yang mempengaruhiatau yang menjadi sebab perubahannnya atau timbulnya variabel terikat (Sugiyono, 2020). Variabel independen pada penelitian ini adalah Tingkat Kebisingan.

Variabel dependen biasa disebut sebagai variabel output. Variabel terikat merupakan variabel yang dipengaruhi atau yang menjadi akibat, karena adanya variabel bebas (Sugiyono, 2020). Variabel dependen pada penelitian ini adalah Stress Kerja.

Instrument penelitian yang digunakan untuk tingkat kebisingan ialah menggunakan lembar observasi dengancara ukur yaitu pengukuran langsung dengan alat ukur Sound Level Meter. Lembar observasi ini untuk mengetahuihasil ukur kebisingan.

Dalam penelitian ini menggunakaninstrumen kuesioner yang diadopsi dari penelitian Silvia Handayani (2016) berupa kuesioner yang berisi 10 pernyataan dengan menggunakan skala Guttman yaitu Ya dan Tidak. Berdasarkan uji validitasyang dilakukan di Area Produksi
Pabrik Kelapa Sawit Rambutan PTPN III Tahun 2016 pada stress kerja sebanyak 10 pertanyaan ialah mendapatkan hasil Rtabel 0,879. Sehingga pertanyaan tersebut dinyatakan valid dan hasil uji reliabilitas yaitu stress kerja dengan jumlah 10 pertanyaan yang diajukan dinyatakanreliabel.

Penelitian ini dilaksanakan pada Bulan Maret-Juni 2020 di Pabrik Batu Alam di Desa Kepuh Kabupaten Cirebon.

\section{HASIL PENELITIAN}

\section{Analisis Univariat}

\section{A. Tingkat Kebisingan}

Tabel 4.1. Distribusi Frequency

Tingkat Kebisingan

\begin{tabular}{ccc}
\hline Tingkat Kebisingan & Frequency & Percent \\
\hline Normal $\leq 85 \mathrm{Db}$ & 12 & 20,3 \\
Bising $\geq 85 \mathrm{~dB}$ & 47 & 79,7 \\
\hline Total & 59 & 100,0 \\
\hline
\end{tabular}

Sumber : Data Primer Terolah2021

Berdasarkan hasil dari tabel 4.1 diperoleh Tingkat Kebisingan Pabrik Batu Alam di Desa Kepuh Kabupaten Cirebon yang melebihi nilai ambang batas $85 \mathrm{Db}$ yaitu $79,7 \%$.

\section{B. Stress Kerja}

Tabel 4.2. Distribusi Frequency Stres Kerja

\begin{tabular}{ccc}
\hline Stres Kerja & Frequency & Percent \\
& & \\
\hline Tidak Stress & 14 & 23,7 \\
Stres & 45 & 76,5 \\
\hline Total & 59 & 100.0
\end{tabular}

Sumber : Data Primer Terolah, 2021

Berdasarkan hasil dari tabel 4.2 diperoleh hasil distribusi frekuensi stress kerja yaitu sebesar 45 dengan jumlah 
presentase $76,5 \%$ pada para pekerja pabrik batu alam di desa kepuh kabupaten Cirebon.

\section{Analisis Bivariat}

\section{A. Tingkat Kebisingan}

Tabel 4.3. Distribusi Hubungan Tingkat

Kebisingan Dengan Stress Kerja Pada

Pekerja Pabrik Batu Alam Di Desa

Kepuh Kabupaten Cirebon

\begin{tabular}{|c|c|c|c|c|c|c|c|}
\hline \multirow{4}{*}{$\begin{array}{c}\text { Tingkat } \\
\text { Kebisinga } \\
\text { n }\end{array}$} & \multicolumn{4}{|c|}{ Stres Kerja } & \multirow{2}{*}{\multicolumn{2}{|c|}{ Total }} & \multirow{3}{*}{$\begin{array}{c}\mathbf{P} \\
\text { Valu } \\
\mathbf{e}\end{array}$} \\
\hline & \multirow{2}{*}{\multicolumn{2}{|c|}{$\begin{array}{l}\text { Tidak } \\
\text { Stres }\end{array}$}} & \multicolumn{2}{|c|}{ Stres } & & & \\
\hline & & & & & & & \\
\hline & $\mathrm{F}$ & $\%$ & $\mathrm{~F}$ & $\%$ & $\mathrm{~F}$ & $\%$ & \\
\hline Normal & 8 & 66 , & 4 & 33 , & 1 & 100. & \\
\hline & & 7 & & 3 & 2 & 0 & \\
\hline Bising & 6 & 12 , & 4 & 87 , & 4 & 100. & \\
\hline & & 8 & 1 & 2 & 7 & 0 & \\
\hline Total & 1 & 23, & 4 & 76 , & 5 & 100 & \\
\hline & 4 & 7 & 5 & 3 & 9 & & \\
\hline
\end{tabular}

Sumber : Data Primer Terolah, 2021

Berdasarkan hasil dari tabel 4.3 dapat diperoleh data responden bahwa adanya stress kerja di kebisingan $>85 \mathrm{db}$ berjumlah 47 responden dengan jumlah presentase $87,2 \%$, sedangkan pekerja yang tidak stress kerja dikebisingan $>85 \mathrm{db}$ berjumlah 6 responden dengan jumlahpresentase $12,8 \%$ serta diperoleh data tidakstress kerja dikebisingan normal $<85 \mathrm{db}$ yaitu sebesar 8 responden dengan jumlah presentase $66,7 \%$ dan terakhir adanyastress dikebisingan normal $<85 \mathrm{db}$ yaitu 4 responden dengan jumlah persentase $33,3 \%$. Dengan hasil $p$ value yang diperoleh sebesar 0,000 hasil analisis bivariat antara kedua variabel yaitu Tingkat Kebisingan diperoleh $\mathrm{H}_{0}$ ditolak dan $\mathrm{H}_{\mathrm{a}}$ diterima yang artinya ada hubungan Tingkat Kebisingan DeganStress Kerja Pada Pekerja Pabrik Batu Alam Di Desa Kepuh Kabupaten Cirebon. Nilai tersebut lebih kecil daripaa nilai $\alpha=0,05$.

\section{A. Tingkat Kebisingan}

Berdasarkan Peraturan Menteri Tenaga Kerja dan Transmigrasi Nomor 13 Tahun 2011, kebisingan adalah semua suara yang tidak dikehendaki yang bersumber dari alat-alat proses produksi dan atau alatalat kerja yang pada tingkat tertentu dapat menimbulkan gangguan pendengaran. Kebisingan merupakan masalah yang sampai sekarang belum bisa ditanggulangi secara baik karena merupakan salah satu faktor yang diabaikan dari lingkungan kerja sehingga dapat menjadi ancaman serius bagi kesehatan para pekerja (Rahmawati, 2015).

Bising adalah sesuatu yang tidak dapat kita hindari dalam kehidupan sehari-hari, termasuk di tempat kerja. Bahkanbunyi yang kita tangkap melalui telinga kita merupakan bagian dari kerja misalnya, bunyi telepon, bunyi mesin ketik, mesincetak dan sebagainya. Namun seringnyabunyi-bunyi tersebut meskipun merupakanbagian dari kerja kita, tetapi tidak kitainginkan. Misalnya teriakan orang, bunyi mesin diesel yang melebihi ambang batas pendengaran, bunyi yang tidak kitainginkan inilah yang serig disebut bising atau kebisingan (Notoatmodjo, 2011).

Dapat disimpulkan bahwa tingkat bising di lingkungan pabrik batu alam di Desa Kepuh Kabupaten Cirebon sebagian besar ada di dalam kebisingan lebih dari $85 \mathrm{db}$ dengan presentase 79,7\%.

Hal tersebut juga sesuai dengan penelitian yang dilakukan oleh OlyviaRismayana (2020). Penelitian ini berjudul Hubungan Tingkat Kebisingan Alat Pengolahan Kayu Dengan Keluhan Pendengaran Subyektif Pada Pekerja Pengrajin Meubel di Wilayah Kerja Puskesmas SindangJawa Kabupaten Cirebon Tahun 2020. Pekerja mengalami kebisingan lebih dari $85 \mathrm{db}$ dengan persentase $97,0 \%$.

\section{B. Stress Kerja}

\section{PEMBAHASAN}

Fajr Lintang Pinilih et al., Hubungan Tingkat Kebisingan Dengan Stress Kerja Pada Pekerja Pabrik ... 
Stress kerja (occupational stress) menurut Wijono (2010:122) merupakan suatu kondisi dari hasil penghayatan subyektif individu yang dapat berupa interaksi antara individu dan lingkungankerja yang dapat mengancam dan memberi tekanan secara psikologis, fisiologis dansikap individu. Stress kerja (occupational stress) merupakan perwujudan dari kekaburan peran, konflik peran dan beban kerja yang berlebihan.

Berdasarkan hasil penelitian yang didapatkan sebagian besar responden mengalami stress kerja sebanyak 45 pekerja dengan jumlah presentase 76,5 $\%$ pada para pekerja pabrik batu alam di desa kepuh kabupaten Cirebon. Hal ini disebabkan oleh intensitas kebisingansetiap harinya sebesar $>85 \mathrm{db}$.

\section{Hubungan Tingkat Kebisingan Dengan Stress Kerja Pada Pekerja Pabrik Batu Alam Di Desa Kepuh Kabupaten Cirebon}

Berdasarkan hasil penelitiandiketahui bahwa sebagaian besar area produksi pabrik bising $(79,7 \%)$ akibatfaktor lingkungan yang kurang nyaman yaitu suara mesin produksi yang bising melebihi Nilai Ambang Batas (NAB) tenyata berhubungan kuat dengan stress pada pekerja yang bekerja di pabrik batu alam. Hasil uji Chi-Square diperoleh bahwa ada hubungan yang signifikan antara kebisingan dengan stress kerja.Semua pekerja cenderung memiliki area bising. Hal ini dikarenakan suara bisingyang ada di area produksi pabrik sebesar $>85 \mathrm{db}$ yang mengakibatkan pekerja sulit berkonsentrasi saat bekerja, tidak nyaman bekerja dari alat-alat kerja dan mudah terpancing emosi.

Lingkungan kerja merupakan salah satu sumber utama bahaya potensial kesehatan kerja. Salah satu dari faktor yang terdapat dalam lingkungan kerja adalah kebisingan. Kebisingan di tempat kerja seringkali merupakan problem tersendiri bagi tenaga ke rja, umumnya berasal dari mesin kerja. Sayangnya, banyak tenaga kerja yang telah terbiasa dengan kebisingan tersebut, meskipun tidak mengeluh gangguan kesehatan tetap terjadi, sedangkan efek kebisingan terhadap kesehatan tergantung pada intensitasnya. Kebisingan dapat menimbulkan efek berupa gangguan fisiologis, psikologis salah satu contoh gangguan psikologis yang diakibatkan oleh kebisingan adalah stres kerja. Ketika tubuh mendapatkan tekanan dari stressor berupa suara bising tuuh bereaksi secara emosi dan fisis untuk mempertahankan kondisi fisis yang optimal reaksi ini disebut General Adaption Syindrom (GAS).

Di tempat kerja, terdapat beberapa faktor yang mempengaruhi lingkungan kerja seperti faktor fisik, faktor kimia, faktor biologis dan faktor psikologis. Semua faktor tersebut dapat menimbulkan gangguan terhadap suasana kerja dan berpegaruh terhadap kesehatan dan keselamatan kerja. Salah satu upaya pekerja untuk mengurangi keluhan gangguan pada kesehatan dengan menjaga diri dengan menggunakan Alat Pelindung Diri (APD) yang sudah ditetapkan oleh peraturan yang diatur dalamPERMENAKERTRANS Nomor PER. 08/MEN/VII/2010 tentang alat pelindung diri pasal 6 yaitu pekerja atau buruh dan orang lain yang memasuki tempat kerja wajib menggunakan APD sesuai denganpotensi bahaya dan risiko di tempat kerja sehingga dapat terlindungi walau dalam konsisi bising dengan intensitas yang tinggi.

Sejalan dengan penelitian Aripta Pradana (2013) menunjukkan ada hubungan yang bermakna antara Kebisingan Dengan Stress Kerja PadaPekerja Bagian Gravity PT. Dua Kelinci dengan nilai $p=0,000$.

\section{KESIMPULAN}

Berdasarkan hasil pengukuran kebisingan yang dilakukan di lapangan dengan alat Sound Level Meter dan pengolahan data yang dilakukan dengan program computer SPSS serta analisisvariabel yang diteliti tentang hubungan tingkat kebisingan dengan stress kerjapada 
pekerja pabrik batu alam di Desa Kepuh Kabupaten Cirebon dapat disimpulkan bahwa:

1. Hasil dari pengukuran tingkat kebisingan yang dilakukan di lapangan secara langsung di Pabrik Batu Alam di Desa Kepuh Kabupaten Cirebon didapatkan hasilnya yaitu melebihi nilai ambang batas $85 \mathrm{db}$ dengan persentase $79,7 \%$.

2. Hasil dari pengolahan data yang telah dilakukan hasil dari distribusi frekuensi stress kerja yaitu sebesar 45 responden mengalami stress kerja dengan jumlah presentase $76,5 \%$ padapara pekerja pabrik batu alam di desa kepuh kabupaten Cirebon.

3. Dengan hasil $p$ value yang diperoleh sebesar 0,000 dari hasil analisis bivariat antara kedua variabel yaitu Tingkat Kebisingan diperoleh $\mathrm{H}_{0}$ ditolak dan $\mathrm{H}_{\mathrm{a}}$ diterima yang artinya ada hubungan Tingkat Kebisingan Dengan Stress Kerja Pada Pekerja Pabrik Batu Alam Di Desa Kepuh Kabupaten Cirebon. Nilai tersebut lebih kecil daripaa nilai $\alpha=0,05$.

\section{SARAN}

Berdasarkan dari manfaat penelitian mengenai Tingkat Kebisingan Dengan Stress Kerja Pada Pekerja Pabrik Batu Alam Di Desa Kepuh Kabupaten Cirebon, terdapat saran yang dapat diajukan penelitiadalah sebagai berikut:

1. Bagi Institusi Kampus (STIKes Mahardika Cirebon)

Hasil penelitian ini agar dapat dijadikan sebagai bahan referensi yang bermanfaat dan memberi perkembangan ilmu pengetahuan terutama ilmu kesehatan masyarakat terkait tingkat kebisingan dengan stress kerja pada pekerja pabrik batu alam dalam.

\section{Bagi Peneliti Lain}

Dari hasil penelitian yang sudah dilakukan diharapkan penelitian ini dapat memberikan manfaat, masukan data, sebagai bahan acuan danmemberikan informasi yang dapatdigunakan sebagai bahan pustaka untuk pengembangan ilmu kesehatan lingkungan dan kesehatan dan keselamatan kerja.
3. Bagi Pemilik Pabrik

Diharapkan hasil dari penelitian inidapat dijadikan bahan evaluasi dalam mengelola usaha, khususnya dalam menjaga keamanan dan kesehatan para pekerja dengan menyediakan Alat Pelindung Telinga seperti sumbat telinga (Ear Plug) dan tutup telinga (Ear Muff) yang dapat digunakan oleh pekerja pada saat di lingkungan kerjanya, agar tidak mengalami Penyakit Akibat kerja (PAK).

4. Bagi Tenaga Kerja

Diharapkan hasil dari penelitian ini agar para pekerja lebih dapat melindungi diri sendiri dan menjaga kesehatannya agar tidak mengalami stress kerja atau penyakit akibat kerja yang dapat mengganggu kesehatan dirinya, dengan cara mencegahnya menggunakan Alat Pelindung Diri berupa alat pelindung telinga yang sesuai dengan ketetapan peraturan yang diatur oleh pemerintah.

\section{REFERENSI}

Asih, Gusti Yuli, dkk. (2018). StressKerja. Semarang: SemarangUniversity Press.

Budiawan, Wiwik, dkk. (2016). Analisis Hubungan Kebisingan Mesin Dengan Stress Kerja. Jurnal PRESIPITASI. Vol 13. No1. (Diunduh Pada tanggal 31 Januari 2021, Pukul 20.37).

Budiyanto, Tri \& Pratiwi, Erza Yanti. (2010). Hubungan Kebisingan Dan Masa Kerja Terhadap Terjadinya Stress Kerja Pada Pekerja Di Bagian Tenun "Agung Saputra Tex" Piyungan Bantul Yogyakarta. JURNAL KESMAS. Vol 4. No 2. (Diunduh Pada tanggal 31 Januari 2021, Pukul 22.10).

Fachriani, Faisal. (2019). Hubungan Riwayat Ibu Selama Kehamilan Dengan Kejadian Berat Badan Lahir Rendah di Wilayah Kerja Dinas Kesehatan Kota 
Cirebon. Skripsi. Ilmu Keperawatan STIKes MahardikaCirebon, Cirebon.

Gani, Lathifa Rusyda, dkk. (2018). Hubungan antara Kebisingan diTempat Kerja denganKualitas Tidur pada Pekerja Pabrik Kayu PT. Muroco Jember. Jurnal of Agromedicine andMedical Sciences. Vol 4. No 2. (Diunduh pada tanggal 1 Februari 2021, pukul 20.35).

Handayani, Silvia. (2016). Pengaruh Kebisingan Terhadap Stress Kerja Pada Karyawan Di Area Produksi Pabrik Kelapa SawitRambutan PTPN III Tahun 2016. Tesis. Fakultas Kesehatan Masyarakat Universitas Sumatera Utara. (Diunduh pada tanggal 10 Maret 2021 pukul 21.38).

Haq, Dinul. (2018). Pengaruh Tingkat Intensitas Kebisingan Gangguan Psikologis, Komunikasi, Fisiologis Terhadap Kinerja Karyawan Di PT. Allied Indo Coal Jaya. Tugas Akhir. Teknik PertambanganYayasan Muhammad YaminSekolah Tinggi Teknologi Industri (STTIND) Padang.

Hiola, Reni \& Sidiki, Atris K. (2016). Hubungan Kebisingan Mesin Tromol Dengan Stress Pekerja di Kabupaten Bone. Unnes Journal of Public Health. Vol.5. No. 4. (Diunduh pada tanggal 4 Februari 2021, Pukul 23.33 WIB).

International Labour Organization. (2013). Keselamatan dan Kesehatan Kerja.Jakarta: ILO

Jundillah, Zhafarina Nastiti, dkk. (2017). Analisis Kejadian Stress Kerja Pada Perawat Di Kabupaten Konawe Kepulauan Tahun 2017. JIMKESMAS (Jurnal Ilmiah Kesehatan Masyarakat). Vol. 2. No.6. (Diunduh pada tanggal 6 Februari 2021, pukul 22.36).

Meigawati, Kristin. (2013). Pengaruh Stress Kerja dan GayaKepemimpinan Terhadap KinerjaKaryawan
(Studi pada karyawan Perusahaan Daerah Bank Perkreditan Rakyat Badan Kredit Kecamatan Purwodadi). Tesis. Fakultas Ekonomi dan Bisnis Universitas Katolik SoegijapranataSemarang.

Nadhiroh, MH. 2011. Hubungan Paparan Kebisingan Dengan Stress KejaPada Tenaga Kerja Di Bagian Weaving PT. Triangga Dewi Surakarta. Skripsi. Fakultas Kedokteran. Universitas Sebelas Maret. Surakarta. (Diunduh pada tanggal 31 Januari 2021, Pukul 21.00).

Notoatmodjo. (2018). Metodologi Penelitian Kesehatan. Jakarta: PT. Rhineka Cipta

Nurika Yulianty, Maharani. (2018). Hubungan Antara Perilaku Asertif Dengan Stress Kerja Pada Anggota Brimob Detasemen B Pelopor Sat Brimob Polda Nusa Tenggara Barat. Skripsi Thesis. Universitas Mercu Buana Yogyakarta. (Diunduh pada tanggal5 Maret 2021, Pukul 07.00).

Nursalam. (2015). Metodologi Penelitian Ilmu Keperawatan. Jakarta :Salemba Medika

Pradana, Aripta. (2013). Hubungan Antara Kebisingan Dengan Stress Kerja Pada Pekerja Bagian Gravity PT. Dua Kelinci. Skripsi. Fakultas Ilmu Keolahragaan Universitas NegeriSemarang.

Rahmadanti, Nurul. (2019). Hubungan Intensitas Kebisingan, BebanKerjadan Masa Kerja Dengan Terjadinya Stress Kerja Pada Karyawan PT.Inti Vulkatama Padang Tahun 2019.

DiplomaThesis. Universitas Andalas.

Ramlan, Jamaludin \& Sumihardi. (2018). Sanitasi Industri dan K3. Jakarta: Kementerian Kesehatan Republik Indonesia.

Rismayana, Olyvia. (2020). Hubungan Tingkat Kebisingan Alat Pengolahan Kayu Dengan Keluhan Pendengaran Subyektif Pada Pekerja Pengrajin Meubel di Wilayah Kerja Puskesmas SindangJawa Kabupaten Cirebon Tahun 2020. 
Skripsi. KesehatanMasyarakat STIKes Mahardika

Cirebon.

Rusdi,dkk. (2019). Hubungan Beban Kerja Dan Gaya Kepemimpnan Dengan Tingkat Stress Pada Tenaga Kesehatan Di Puskesmas Handil Baru. Jurnal Medika Karya Ilmiah Kesehatan. Vol. 4. No.2. (Diunduh pada tanggal 14 Februari 2021, pukul 19.30 WIB).

Tambunan, Anggiat Parluhutan. (2018). Lingkungan Kerja dan Kepuasan Kerja Karyawan: Suatu Tinjauan Teoritis. Jurnal Ilmiah Methonomi. Vol. 4. No. 2. (Diunduh pada tanggal 20 Februari, Pukul 22.44).

Tim K3 FT UNY. 2014. Keselamatan dan Kesehatan Kerja (K3). Yogyakarta: Universitas Negeri Yogyakarta. Yusmardiansyah \& Zhara, Ghania. (2019).Hubungan Kebisingan Dengan Stress Kerja Pada PekerjaBagian Produksi Di PT. Mitra Bumi. PREPOTIF Jurnal Kesehatan Masyarakat. Vol.3. No 2. (Diunduh pada tanggal 5 Februari 2021, Pukul 19.00). 